\title{
Powering the Sustainable Development Goals for Green Growth in Nigeria
}

Kehinde Adekunle Adetiloye (Covenant University, Nigeria), Abiola Ayopo Babajide (Covenant University, Nigeria) and Joseph Niyan Taiwo (Covenant University, Nigeria)

\section{Abstract}

This chapter is on the use of the Sustainable Development Goals (SDGs) for the achievement of green economy in Nigeria with the specific aim of assessing the performance of key issues in the SDGs. Five goals SDGs 6, 7, 11, 12, and 15 for water and sanitation, safe human settlements, renewable energy, sustainable consumption and production, and ecosystem, respectively, are selected for assessment for the green initiatives and the economy. Budgets on economic and social services follows the pattern theory: that government allocates and reallocates at will without cognizance of the population's interests. The assessment holds the fact that only two of these goals are being met somehow_renewable energy and clean water-and not necessarily because of the need to achieve the goals but as part of private sector and dynamic market initiatives, clearly indicating failures for the others. For the most part, Nigeria failed in the areas of ecosystem, good human settlement, and responsible consumption. The chapter suggests the encouragement of entrepreneurial initiatives, the initiation of new policies on green economy, and the enforcement of regulations already in place to power the economy.

\section{Key Terms in this Chapter}

Renewable Energy: Energy production from sources that can be regenerated and are not wasting fossils. Such energy sources include natural ones like recyclable sources and naturally occurring phenomenon like sunlight and is generally reproducible.

Ecosystem: The interrelation of the various groups of fauna and flora in the environment to sustain lives of the various living organisms on a sustainable basis.

Clean Water: Provisions of clean potable water for human consumption and use.

Sustainable Production: One of the goals promoted by the SGDs that encourages the production of consumables that avoids waste and `encourage long term production.

Housing: The man man-made habitation for human beings that are constructed in taste and style as desired by the owner.

Green Economy: An economy that takes cognizance of avoiding the injurious production and consumption and allows the regeneration of the natural products rather than synthetic products.

Sustainable Development Goals: The up-scaled goals promoted by the United Nations as a successor to the MDGs. It has 17 goals and is due to end by 2030.

Millennium Development Goals: The eight goals promoted by the United Nations for performance up till 2015. The goals address the issues of poverty and basic human existence. 